\title{
AVALIAÇÃO DE VARIÁVEIS FISIOLÓGICAS EM PORTA-ENXERTOS DE VIDEIRA CULTIVADOS EM SOLUÇÃO NUTRITIVA COM A ADIÇÃO DE ALUMÍNIO
}

\author{
Physiologic variables evaluation in grapevine roostocks grown in nutritive \\ solution with aluminum addition
}

\author{
Marco Antonio Tecchio ${ }^{1}$, Erasmo José Paioli-Pires ${ }^{2}$, Hélio Grassi Filho ${ }^{3}$, Rubem Marcos de Oliveira Brizola ${ }^{4}$, \\ Cássia Regina Yuriko Vieira ${ }^{1}$, Maurilo Monteiro Terra ${ }^{2}$
}

\section{RESUMO}

Realizou-se este experimento com o objetivo de avaliar a resposta dos porta-enxertos de videira IAC 313 "Tropical” e IAC 572 "Jales” a diferentes níveis de alumínio em solução nutritiva. A condução do experimento foi realizada em condições de casa-de-vegetação do Departamento de Produção Vegetal/Área de Horticultura, da Faculdade de Ciências Agronômicas UNESP/Botucatu. Utilizaram-se cinco níveis de alumínio, a saber: 0, 10, 20, 30 e $40 \mathrm{mg} \mathrm{L}^{-1}$. Após a aplicação dos tratamentos, realizaram-se coletas a cada 15 dias para obtenção das variáveis fisiológicas. O delineamento experimental adotado foi o de parcelas subdivididas, inteiramente casualizado e com 3 repetições. Avaliaram-se as variáveis: taxa de crescimento absoluto e relativo, razão de massa foliar e relação parte aérea/raízes. Concluiu-se que o porta-enxerto IAC 572 "Jales”, quando submetido ao nível de $10 \mathrm{mg} \mathrm{Al} \mathrm{L}^{-1}$ na solução, apresentou maior taxa de crescimento absoluto e relativo, e maior redistribuição de massa seca das folhas para o restante da planta, ao passo que o porta-enxerto IAC 313 “Tropical”, quando submetido a esse nível de alumínio, apresentou um decréscimo acentuado nessas variáveis.

Termos para indexação: Vitis, porta-enxertos, tolerância, massa foliar, crescimento.

\begin{abstract}
The experiment aimed to evaluate the behavior of the grapevine rootstocks IAC 313 “Tropical” and IAC 572 "Jales" in nutrient solution with different aluminium concentrations. The experiment was conducted in green house conditions of the Vegetal Production Department/Horticulture Sector, of the Faculty of Agricultural Sciences - UNESP/Botucatu. Five aluminium levels were used, as known: 0, 10, 20, 30 and 40mg L-1 in the form of AlCl3.6H2O. The samples were colleted every 15 days to obtain the physiologic variables. The experimental design adopted was the subdivided split-plots, fully randomized and with 3 replications. The variables evaluated were: absolute and relative growth rates, leaf weight and aerial parts/root ratio. The IAC 572 "Jales" rootstock, when grown in $10 \mathrm{mg} \mathrm{Al} \mathrm{L}^{-1}$ in the solution, presented higher absolute and relative growth rates and higher dry matter redistribution from leaves to other plant parts. The IAC 313 "Tropical” rootstock, in the same condition, presented a sharp decrease of these variables.
\end{abstract}

Index terms: Vitis, rootstocks, tolerance, leaf weight, growth.

(Recebido para publicação em 26 de abril de 2004 e aprovado em 20 de Janeiro de 2005)

\section{INTRODUÇÃO}

A toxidez causada pelo alumínio é um dos mais importantes fatores que limitam o crescimento e/ou o desenvolvimento das plantas em solos ácidos, principalmente em pH abaixo de 5,0 (OLMOS \& CAMARGO, 1976). Segundo Fráguas (1996), os efeitos tóxicos do alumínio em videira começam a surgir a partir de 20\% de saturação de alumínio no solo, ocorrendo uma drástica redução no crescimento das plantas à medida que o nível de saturação ultrapassa os $40 \%$. Malavolta (1980) considerou como prejudicial às plantas teores de alumínio trocável no solo valores superiores a 5,0 $\mathrm{mmol}_{\mathrm{C}} \mathrm{dm}^{-3}$.

A fitotoxidez do alumínio manifesta-se, principalmente, pela inibição do crescimento das raízes dos vegetais, o que traz conseqüências negativas sobre a nutrição mineral e sobre a absorção de água (FOY \& FLEMING, 1978). Segundo Foy (1976), essa toxidez é

1. Doutorando do Departamento de Produção Vegetal/Área Horticultura da UNESP - Faculdade de Ciências Agronômicas, Caixa Postal 237 - $18603-970$ Botucatu,SP - Ex-Bolsista do CNPq - tecchio@iac.sp.gov.br

2. Pesquisador Científico, Instituto Agronômico de Campinas - Caixa Postal 28 - 13001-970 - Campinas - SP

3. Professor Adjunto do Departamento de Recursos Naturais/Área Ciências do Solo da UNESP - Faculdade de Ciências Agronômicas.

4. Engenheiro Agrônomo M.Sc. Assessoria e Projetos em Fruticultura - Alberto Mosmann, 304, - Parobé, RS - 95630-000. 
especialmente prejudicial nos subsolos ácidos, por restringir o aprofundamento das raízes e as suas ramificações, contribuindo para um decréscimo da tolerância à seca e o acesso aos nutrientes das camadas mais profundas. A fitotoxidez é caracterizada morfologicamente pelo engrossamento e paralisação do crescimento das raízes, devido ao enrijecimento da parede e à inibição da divisão celular (FOY \& FLEMING, 1978) e, fisiologicamente, pela alteração da absorção e utilização de nutrientes, principalmente o fósforo (FOY, 1997).

A toxicidade de alumínio na parte aérea das plantas freqüentemente se assemelha aos sintomas de deficiência de cálcio e de fósforo, em conseqüência da interação de alumínio na absorção e transporte desses elementos (FOY, 1974). Em muitas espécies, a tolerância ao alumínio está intimamente relacionada com a habilidade das plantas em adquirir nutrientes na presença de alumínio, principalmente com relação ao fósforo e/ou cálcio (BENNET et al., 1986; FOY et al., 1972; HUANG et al., 1992).

No Brasil, Costa (1998), Gergoletti (1995), Lopes (1983) e Regina et al. (1998), realizaram levantamentos de solos em algumas regiões produtoras de uva, nas quais, evidenciaram-se com freqüência problemas relacionados à baixa fertilidade do solo, como alta acidez, elevados teores de alumínio trocável e baixa capacidade de troca catiônica.

De acordo com Fregoni (1980), e Marcelin (1974), o porta-enxerto “196-17CL” é considerado tolerante a solos ácidos e os porta-enxertos "R99" e "Rupestris du Lot” são mais sensíveis à acidez. No Brasil, em experimentos realizados por Fráguas (1999), concluiu-se que os porta-enxertos "R99”, "Rupestris du Lot” e "Kober 5BB" e a produtora direta "Isabel” foram os mais sensíveis ao alumínio, e o “P1103”, “RR 101-14” e “196-17Cl” foram os mais tolerantes. Alvarenga (2001), realizando experimento em condições de casa-devegetação, verificou que os porta-enxertos “IAC 572” e
"Gravesac" foram os mais tolerantes ao alumínio e o “Kober 5BB” foi o mais sensível. Nos experimentos realizados em campo, Alvarenga (2001), verificou que o porta-enxerto “IAC 313” retardou a maturação dos frutos nas copa "Folha de figo", “Jacquez” e "Niagara Rosada” e o "IAC 572” proporcionou maiores cachos às referidas copas.

Nesses experimentos, não foram avaliadas as variáveis fisiológicas dos porta-enxertos de videira em condições de fadiga por alumínio. De acordo com Radford (1967), essas variáveis refletem as condições morfo-fisiológicas das plantas durante o seu ciclo ontogênico, sendo de extrema importância para avaliar o crescimento e desenvolvimento das plantas. Com base no exposto, com o presente trabalho objetivou-se avaliar algumas variáveis fisiológicas dos portaenxertos de videira IAC 313 “Tropical” e IAC 572 “Jales” em níveis crescentes de alumínio em solução nutritiva. Sabe-se que, atualmente, esses portaenxertos são os mais propagados na viticultura tropical brasileira, encontrando-se poucos estudos relacionados à maior ou menor tolerância dessas cultivares quando submetidas a solos com elevados teores de alumínio.

\section{MATERIAL E MÉTODOS}

Realizou-se o experimento no Departamento de Produção Vegetal/Área Horticultura, da Faculdade de Ciências Agronômicas-UNESP/Botucatu, no período de 05/07/2001 a 03/02/2002, sob condição de casa-devegetação com temperatura ajustada a $25^{\circ} \mathrm{C}$ e umidade relativa do ar a 50\%. Os levantamentos dos dados médios de temperatura e umidade relativa do ar foram realizados semanalmente por um termo-higrógrafo colocado a 2,0 m de altura, no centro da área experimental. As variações ocorridas nesses fatores podem ser observadas na Tabela 1.

TABELA 1 - Valores médios de temperatura, em ${ }^{\circ} \mathrm{C}$, e umidade relativa do ar, em \%, registrados durante a realização do experimento. FCA/UNESP, Botucatu/SP, 2004.

\begin{tabular}{lcccccccc}
\hline \multirow{2}{*}{ Fatores ambientais } & \multicolumn{9}{c}{$\mathbf{c 0 0 1}$} & \multicolumn{2}{c}{$\mathbf{2 0 0 2}$} \\
\cline { 2 - 9 } & Jul. & Ago. & Set. & Out. & Nov. & Dez. & Jan. & Fev. \\
\hline Temperatura & 19,4 & 21,9 & 25,2 & 26,9 & 26,8 & 28,4 & 27,5 & 26,5 \\
Umidade & 58 & 47 & 54 & 59 & 56 & 62 & 65 & 58 \\
\hline
\end{tabular}


Os porta-enxertos avaliados foram o IAC 313 “Tropical” e o IAC 572 “Jales”, coletados no Instituto Agronômico de Campinas. Utilizaram-se como material de propagação estacas com 2 gemas, as quais foram no dia 7 de julho de 2001 enraizadas em caixas de madeira contendo areia e vermiculita expandida na proporção 1:1. Realizaram-se, aos 30 e 50 dias após o plantio dos porta-enxertos, 2 irrigações com solução nutritiva completa de Hoagland \& Arnon (1950) a 20\% de sua concentração. O transplante das estacas para as caixas plásticas contendo a solução nutritiva foi realizado em 3 de setembro de 2001, quando as plantas apresentavam brotações com altura de $10 \mathrm{~cm}$, aproximadamente, com 4 a 5 folhas, havendo uma seleção baseada no vigor, na sanidade e no tamanho dos porta-enxertos, para homogeneizar os tratamentos.

O delineamento experimental adotado foi o de parcelas subdivididas, sendo inteiramente casualizado com 3 repetições. Foi realizada a análise de regressão para verificar o comportamento de cada porta-enxerto nos diferentes níveis de alumínio em cada época de coleta e o desenvolvimento das plantas em cada nível de alumínio em função das diferentes épocas de coleta. Nas análises significativas, foram ajustadas equações de regressão.

As caixas plásticas utilizadas no experimento apresentavam um volume útil de 15 litros, sendo cobertas com tampas de madeira com $64 \mathrm{~cm}$ de comprimento com $30 \mathrm{~cm}$ de largura. Em cada caixa, colocaram-se 10 plantas, distanciadas $10 \mathrm{~cm}$ uma da outra, apoiadas sobre as tampas de madeira. A aeração da solução nutritiva foi realizada duas vezes ao dia, de manhã e à tarde, com duração de uma hora cada uma, sendo o ar conduzido às caixas através de tubos plásticos ligados a um compressor de ar. Antes da aplicação dos tratamentos, as plantas passaram por um processo de aclimatação, segundo os critérios utilizados por Terra (1984).

A composição da solução nutritiva seguiu as recomendações de Furlani \& Furlani (1988), modificada por Santos (1998). Após a adição da solução nutritiva completa, em decorrência de deficiência de magnésio, houve a necessidade de triplicar sua concentração para $63 \mathrm{mg} \mathrm{L}^{-1}$ solução. A composição da solução nutritiva encontra-se na Tabela 2.

Visando a uma homogeneização da altura das plantas, realizou-se no dia 15 de outubro de 2001 uma poda no broto principal, deixando-o com 2 gemas, quando, vinte e dois dias após, selecionou-se apenas o broto mais vigoroso para ser conduzido em haste única. Quando os brotos apresentavam em média $8 \mathrm{~cm}$ de altura e 4 a 5 folhas, realizou-se no dia 19 de novembro de 2001 a troca da solução nutritiva para a aplicação dos tratamentos, que consistiram na adição de 5 níveis de alumínio, a saber: $0,10,20,30$ e $40 \mathrm{mg}$ de $\mathrm{Al} \mathrm{L}^{-1}$ na forma de $\mathrm{AlCl}_{3} 6 \mathrm{H}_{2} \mathrm{O}$. A partir dessa data, realizou-se a coleta de duas plantas por caixa a cada 15 dias para a obtenção dos dados de massa seca das folhas, parte aérea, raiz e total da planta, para o cálculo das variáveis fisiológicas. Dessa maneira, foram realizadas coletas de plantas aos 15, 30, 45, 60 e 75 dias após a aplicação dos tratamentos, avaliando as seguintes variáveis fisiológicas:

Taxa de crescimento absoluto (TCA) - variação ou o incremento entre duas amostragens (BENINCASA, 1988), sendo expressa $\mathrm{g} \mathrm{dia}^{-1}$, calculada ao longo do ciclo pela expressão:

$$
\mathrm{TCA}=\mathrm{MS}_{2}-\mathrm{MS}_{1} / \mathrm{t}_{2}-\mathrm{t}_{1}
$$

Em que:

$\mathrm{MS}_{1} / \mathrm{MS}_{2}-$ massa seca total de 2 coletas sucessivas. $\mathrm{t}_{1}$ e $\mathrm{t}_{2}$ - período das duas amostragens sucessivas.

TABELA 2 - Composição da solução nutritiva de acordo com Furlani \& Furlani (1988), modificada por Santos (1998). FCA/UNESP, Botucatu/SP, 2004.

\begin{tabular}{ccccccc}
\hline \multicolumn{7}{c}{ Macronutrientes $\left(\mathbf{m g ~ L}^{-\mathbf{1}}\right)$} \\
\hline $\mathbf{N}-\mathbf{N O}_{3}{ }^{-}$ & $\mathbf{N}-\mathbf{N H}_{\mathbf{4}}{ }^{+}$ & $\mathbf{P}$ & $\mathbf{K}$ & $\mathbf{C a}$ & $\mathbf{M g}$ & $\mathbf{S}$ \\
147,9 & 18,0 & 1,0 & 86,1 & 140,0 & 21,0 & 17,6 \\
\hline $\mathbf{7}$ & $\mathbf{7}$ Micronutrientes $\left(\mathbf{m g ~ L}^{-\mathbf{1}}\right)$ \\
\hline 5,0 & $\mathbf{B}$ & $\mathbf{C u}$ & $\mathbf{M n}$ & $\mathbf{Z n}$ & $\mathbf{M o}$ & $\mathbf{C l}$ \\
\hline
\end{tabular}


Taxa de crescimento relativo (TCR) - relaciona o aumento da massa seca de uma planta ou qualquer órgão, num dado intervalo de tempo, em função do tamanho inicial (BENINCASA, 1988), expressa em $\mathrm{g} \mathrm{g}^{-1}$ dia $^{-1}$, definida pela expressão:

$$
\mathrm{TCR}=\operatorname{lnMS} \mathrm{S}_{2}-\ln \mathrm{MS}_{1} / \mathrm{t}_{2}-\mathrm{t}_{1}
$$

Em que:

$\mathrm{MS}_{1} / \mathrm{MS}_{2}-$ massa seca total de duas coletas sucessivas. $\mathrm{t}_{1}$ e $\mathrm{t}_{2}$ - período das duas amostragens sucessivas.

Razão de massa foliar (RMF) - avalia a relação fonte-dreno, expressando a quantidade massa seca produzida na fotossíntese não exportada das folhas para o resto da planta (BENINCASA, 1988), sendo calculada pelo quociente entre a massa da matéria seca de folha (MSF) e a massa da matéria seca total (MST). É expressa em $\mathrm{g} \mathrm{g}^{-1}$

$$
\mathrm{RMF}=\mathrm{MSF} / \mathrm{MST}
$$

Em que:

MSF e MST - massa seca das folhas e massa seca total.

Relação Parte Aérea/Sistema Radicular (MSPA/MSR) - analisa o crescimento da parte aérea em relação ao crescimento das raízes. É obtida pela equação (LUCHESI, 1984), expressa em $\mathrm{g} \mathrm{g}^{-1}$ : MSPA $/$ MSR $=($ MSC + MSF $) /$ MSR

Em que:

MSPA - Massa Seca da Parte Aérea

MSC - Massa Seca do Caule.

MSR - Massa Seca das Raízes.

MSF - Massa Seca das Folhas.

Com relação à solução nutritiva, o pH e a condutividade elétrica foram medidos a cada dois dias, havendo também a reposição de água à medida que o nível da solução diminuía. Nos tratamentos sem e com alumínio, o pH da solução manteve-se na faixa de 6,0 a 6,5 e 4,0 a 4,4, respectivamente, não havendo necessidade de correção, pois houve poucas variações. A condutividade elétrica da solução foi usada como indicador para a troca da solução nutritiva, quando atingia valores inferiores a $1,5 \mathrm{mS} \mathrm{cm}^{-1}$.

\section{RESULTADOS E DISCUSSÃO}

Taxa de crescimento absoluto - Na Tabela 3 verifica-se os valores da taxa de crescimento absoluto para ambos os porta-enxertos. O porta-enxerto IAC 313 “Tropical” apresentou maiores valores no tratamento sem alumínio, já que, no período de 60 aos 75 dias, houve um aumento na massa seca total da planta de $0,175 \mathrm{~g} \mathrm{dia}^{-1}$, sendo o resultado máximo obtido nessa variável. Na média das cinco coletas nos diferentes tratamentos, observou-se que ocorreu uma diminuição na taxa de crescimento absoluto com o aumento do alumínio na solução nutritiva, sendo que a maior $\left(0,126 \mathrm{~g} \mathrm{dia}{ }^{-1}\right) \mathrm{e}$ a menor $\left(0,020 \mathrm{~g} \mathrm{dia}^{-1}\right)$ médias obtidas nos tratamentos sem alumínio e no nível de $40 \mathrm{mg}$ de $\mathrm{Al} \mathrm{L}^{-1}$, respectivamente.

Em relação ao porta-enxerto IAC 572 “Jales", a maior taxa de crescimento absoluto foi obtida no nível de $10 \mathrm{mg}$ de $\mathrm{Al} \mathrm{L}^{-1}$ na solução, sendo o maior valor encontrado de $0,220 \mathrm{~g} \mathrm{dia}^{-1}$ no período de $60 \mathrm{a}$ 75 dias. Notou-se que, na média das cinco coletas nos diferentes níveis de alumínio, o nível de $10 \mathrm{mg}_{\mathrm{de}} \mathrm{Al} \mathrm{L}^{-1}$ proporcionou a maior taxa de crescimento absoluto $\left(0,950 \mathrm{~g} \mathrm{dia}^{-1}\right)$ quando comparada com os outros tratamentos.

Medeiros et al. (1990), ao analisarem o crescimento das cultivares de batata-doce "Coquinho" e "Princesa" em coletas realizadas quinzenalmente dos 15 aos 135 dias, obtiveram um aumento na taxa de crescimento absoluto até os 75 dias, havendo uma queda aos 105 dias e um novo pico aos 120 dias. Segundo os autores, a taxa de crescimento absoluto foi máxima nos mesmos períodos em que a área foliar foi máxima, concluindo que a maior taxa de crescimento absoluto é função principalmente da área foliar.

Conforme pode ser visto na Tabela 4, os dois porta-enxertos apresentaram comportamento semelhantes aos obtidos pela taxa de crescimento absoluto. Os portaenxertos IAC 313 "Tropical” e IAC 572 "Jales" apresentaram maiores valores na taxa de crescimento relativo, respectivamente, no tratamento sem alumínio e no nível de $10 \mathrm{mg}$ de $\mathrm{Al} \mathrm{L}^{-1}$ na solução, conforme também verificado na TCA. Para os dois porta-enxertos, em todos os níveis de alumínio, não houve uma tendência geral de diminuição ou aumento dessa variável ao longo do tempo, à exceção do nível de $20 \mathrm{mg} \mathrm{de} \mathrm{Al} \mathrm{L}^{-1}$, para o porta-enxerto IAC 313 “Tropical”, que apresentou uma diminuição progressiva na taxa de crescimento relativo. Medeiros et al. (1990) também obtiveram decréscimo na taxa de crescimento relativo nas cultivares de batatadoce "Coquinho" e "Princesa" com o decorrer do tempo, afirmando que isso ocorreu devido ao aumento gradual de tecidos não-assimilatórios.

Santos (1998) também obteve comportamento variável dessa variável em porta-enxertos cítricos. 
TABELA 3 - Resultados médios da Taxa de Crescimento Absoluto ( $\mathrm{g} \mathrm{dia}^{-1}$ ) da massa seca total dos porta-enxertos IAC 313 “Tropical” e IAC 572 "Jales”, comparando as médias nos diferentes níveis de Al e em cada época de coleta. FCA/UNESP, Botucatu/SP, 2004.

\begin{tabular}{|c|c|c|c|c|c|}
\hline \multirow[b]{2}{*}{ Níveis de $\mathrm{Al}\left(\mathrm{mg} \mathrm{L}^{-1}\right)$} & \multicolumn{4}{|c|}{ Intervalo entre as coletas (dias) } & \multirow[b]{2}{*}{ Média dos níveis de Al } \\
\hline & $15-30$ & $30-45$ & 45-60 & $60-75$ & \\
\hline \multicolumn{6}{|c|}{ Porta-enxerto IAC 313 “Tropical” } \\
\hline 0 & 0,034 & 0,169 & 0,127 & 0,175 & 0,126 \\
\hline 10 & 0,030 & 0,053 & 0,033 & 0,104 & 0,055 \\
\hline 20 & 0,038 & 0,048 & 0,034 & $-0,014$ & 0,026 \\
\hline 30 & 0,027 & 0,066 & 0,003 & 0,061 & 0,039 \\
\hline 40 & 0,021 & 0,015 & 0,030 & 0,014 & 0,020 \\
\hline Média das coletas & 0,030 & 0,070 & 0,045 & 0,068 & \\
\hline \multicolumn{6}{|c|}{ Porta-enxerto IAC 572 “Jales” } \\
\hline 0 & 0,034 & 0,010 & 0,086 & 0,051 & 0,045 \\
\hline 10 & 0,019 & 0,060 & 0,082 & 0,220 & 0,95 \\
\hline 20 & 0,017 & 0,097 & 0,036 & 0,064 & 0,054 \\
\hline 30 & 0,015 & 0,043 & $-0,009$ & 0,059 & 0,027 \\
\hline 40 & 0,017 & 0,033 & 0,005 & 0,072 & 0,032 \\
\hline Média das coletas & 0,020 & 0,049 & 0,040 & 0,093 & \\
\hline
\end{tabular}

Taxa de crescimento relativo

TABELA 4 - Resultados médios da Taxa de Crescimento Relativo $\left(\mathrm{g} \mathrm{g}^{-1} \mathrm{dia}^{-1}\right)$ da massa seca total dos portaenxertos IAC 313 “Tropical” e IAC 572 "Jales”, comparando as médias nos diferentes níveis de Al e em cada época de coleta. FCA/UNESP, Botucatu/SP, 2004.

\begin{tabular}{|c|c|c|c|c|c|}
\hline \multirow[b]{2}{*}{ Níveis de $\mathrm{Al}\left(\mathrm{mg} \mathrm{L}^{-1}\right)$} & \multicolumn{4}{|c|}{ Intervalo entre as coletas (dias) } & \multirow[b]{2}{*}{ Média dos níveis de Al } \\
\hline & 15-30 & 30-45 & $45-60$ & $60-75$ & \\
\hline \multicolumn{6}{|c|}{ Porta-enxerto IAC 313 “Tropical” } \\
\hline 0 & 0,025 & 0,063 & 0,025 & 0,024 & 0,034 \\
\hline 10 & 0,031 & 0,033 & 0,015 & 0,032 & 0,028 \\
\hline 20 & 0,033 & 0,027 & 0,014 & $-0,005$ & 0,017 \\
\hline 30 & 0,028 & 0,041 & 0,001 & 0,023 & 0,024 \\
\hline 40 & 0,019 & 0,010 & 0,017 & 0,007 & 0,013 \\
\hline Média das coletas & 0,027 & 0,035 & 0,015 & 0,016 & \\
\hline \multicolumn{6}{|c|}{ Porta-enxerto IAC 572 “Jales” } \\
\hline 0 & 0,030 & 0,007 & 0,040 & 0,016 & 0,023 \\
\hline 10 & 0,014 & 0,032 & 0,028 & 0,044 & 0,030 \\
\hline 20 & 0,011 & 0,041 & 0,011 & 0,015 & 0,020 \\
\hline 30 & 0,011 & 0,026 & $-0,005$ & 0,026 & 0,014 \\
\hline 40 & 0,014 & 0,022 & 0,003 & 0,030 & 0,017 \\
\hline Média das coletas & 0,016 & 0,025 & 0,015 & 0,026 & \\
\hline
\end{tabular}

Razão de massa foliar 
Para o porta-enxerto IAC 313 "Tropical”, houve interação significativa somente entre as épocas de coletas. Durante o desenvolvimento das plantas, observou-se na Figura 1 que, em todos os níveis de alumínio, com exceção do último, ajustou-se o modelo de regressão linear, havendo um decréscimo da razão de massa foliar durante as coletas. Diminuição na razão de massa foliar durante o desenvolvimento das plantas também foi observado por Aguiar Netto (1997), Rodrigues (1982) e Santos (1998), com as culturas da soja, arroz, batata e citros, respectivamente. Esses resultados corroboram com os de Benincasa (1988), que concluiu que, à medida que a planta cresce, menor é a quantidade de material retido na folha, ou seja, maior é a exportação para outras partes da planta.

Em relação ao porta-enxerto IAC 572 “Jales”, não houve interação significativa entre os níveis de alumínio e as épocas de coletas. Para os níveis de alumínio, observou-se que o nível zero de alumínio apresentou maior razão de massa foliar que os outros tratamentos, sendo ajustado o modelo de regressão quadrática para explicar o decréscimo dessa relação com o aumento do nível de alumínio na solução (Figura 2-A), mostrando que com a adição de alumínio na solução houve uma maior redistribuição de massa seca das folhas para o restante da planta. Com relação às diferentes épocas de coletas, ajustou-se a equação de regressão quadrática (Figura 2-B), mostrando que houve um aumento da razão de massa foliar até os 45 dias após a aplicação dos tratamentos, havendo nesse período um maior acúmulo de massa seca nas folhas em relação à planta inteira. Após os 45 dias, em função de um maior tempo de exposição ao íon alumínio, ocorreu um decréscimo nessa variável. Esses resultados obtidos após os 45 dias corroboram com Aguiar Netto (1997), Benincasa (1988), Rodrigues (1982) e Santos (1998) que obtiveram uma diminuição da relação MSF/MST ao decorrer do tempo.

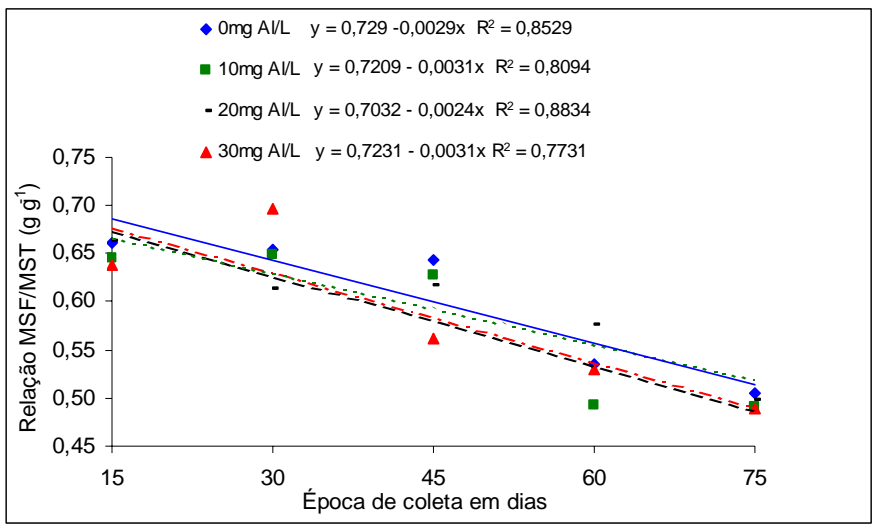

FIGURA 1 - Resultados médios da relação MSF/MST do porta-enxerto IAC 313 “Tropical” nos diferentes níveis de alumínio dos 15 aos 75 dias. FCA/UNESP, Botucatu/SP, 2004.
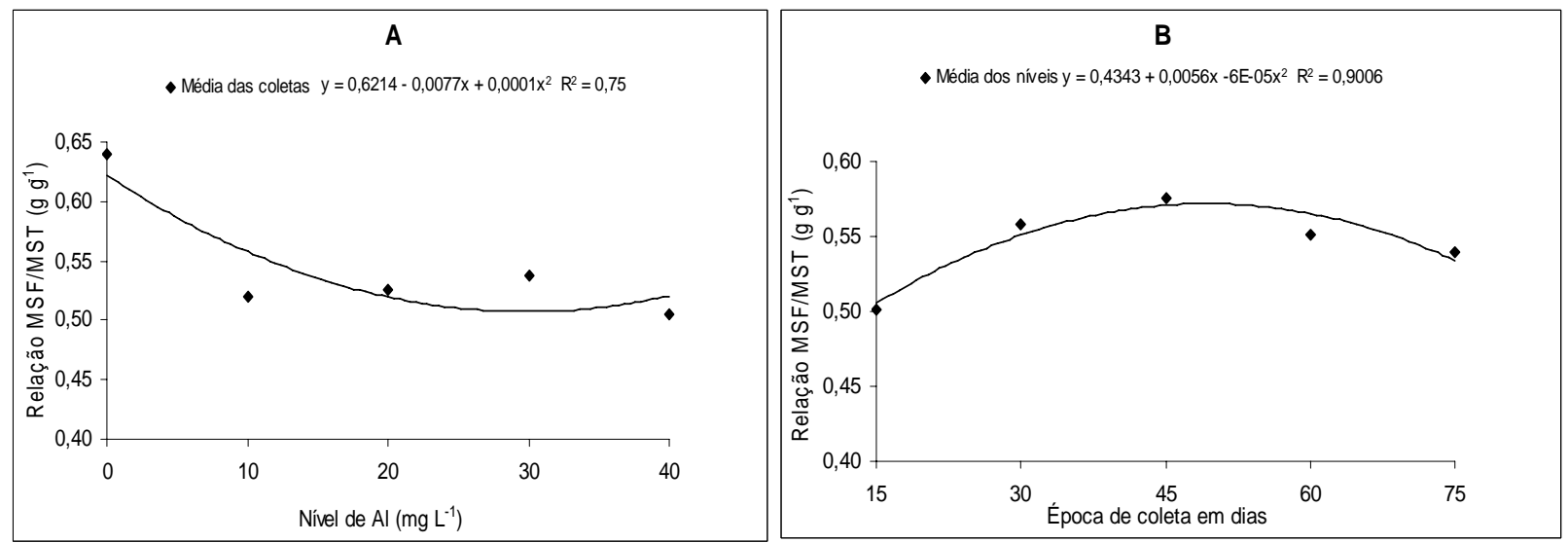

FIGURA 2 - Resultados da relação MSF/MST do porta-enxerto IAC 572 “Jales” em função de níveis crescentes de alumínio na média das épocas de coletas (A) e relação MSF/MST na média dos níveis de alumínio dos 15 aos 75 dias (B). FCA/UNESP, Botucatu/SP, 2004. 


\section{Relação massa seca da parte aérea/massa seca das raízes (PA/R).}

Para o porta-enxerto IAC 313 “Tropical”, houve interação significativa entre os níveis de alumínio e as épocas de coletas. De acordo com a Figura 3-A, o portaenxerto IAC 313 “Tropical” apresentou aos 45, 60 e 75 dias um decréscimo quadrático na relação $\mathrm{PA} / \mathrm{R}$, com o aumento do nível de alumínio na solução nutritiva, havendo, portanto, com a adição de alumínio, um menor desenvolvimento da parte aérea. Resultados semelhantes foram encontrados por Pavan \& Biagham (1982), que obtiveram em cafeeiro uma redução dessa relação com a adição de alumínio na solução. Com relação às épocas de coletas, ajustaram-se equações de regressão apenas para os níveis 0 e $30 \mathrm{mg}$ de $\mathrm{Al} \mathrm{L}^{-1}$, como pode ser visto na Figura 3-B. Notou-se que as plantas que se desenvolveram na ausência de alumínio na solução apresentaram um aumento linear na relação $\mathrm{PA} / \mathrm{R}$, ao passo que no nível de $30 \mathrm{mg}$ de $\mathrm{Al} \mathrm{L}^{-1}$ houve um decréscimo linear. A menor relação parte aérea/raiz com o desenvolvimento da planta também foi verificada por Santos (1998) com porta-enxertos limoeiro "Cravo" e citrumelo "Swingle". No caso do tratamento sem alumínio, o aumento dessa relação durante o período de avaliação foi em função do maior desenvolvimento da parte aérea em relação ao sistema radicular.

O menor desenvolvimento da parte aérea com a adição do alumínio na solução nutritiva deveu-se ao efeito indireto desse íon, que promoveu o encurtamento dos internódios e um menor número de folhas, resultando no menor acúmulo de massa seca da parte aérea. $\mathrm{O}$ efeito direto desse íon manifesta-se inicialmente pela inibição do crescimento radicular, resultando numa redução da divisão e expansão celular. Marschner (1995) mencionou que, provavelmente, a inibição do crescimento celular seja o evento primário e a inibição da divisão celular, como uma resposta aos efeitos sobre o crescimento celular. Segundo Matsumoto (1991), a inibição da divisão celular deve-se à ligação do alumínio ao ADN durante o processo de transcrição celular, impossibilitando sua síntese e, conseqüentemente, paralisando a divisão celular.

Para o porta-enxerto IAC 572 “Jales”, também houve um decréscimo quadrático na relação $\mathrm{PA} / \mathrm{R}$ com o aumento do nível de alumínio na solução, como pode ser visto na Figura 4-A. As plantas que se desenvolveram no nível zero de alumínio na solução foram as únicas a apresentarem aumento linear na relação $\mathrm{PA} / \mathrm{R}$ durante as coletas (Figura 4-B). Isso ocorreu devido ao pequeno desenvolvimento do sistema radicular desse porta-enxerto na ausência de alumínio na solução e ao maior desenvolvimento da parte aérea. Esse resultado discordou dos obtidos por Santos (1998), que verificou um decréscimo nessa relação com o desenvolvimento das plantas.
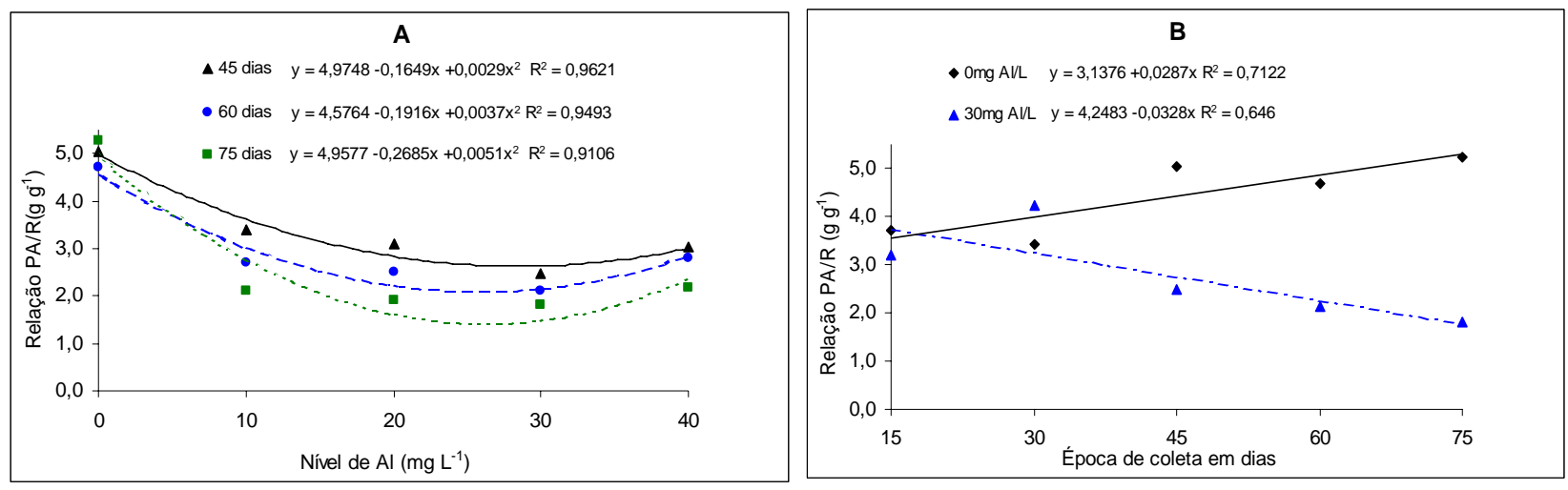

FIGURA 3 - Resultados da relação PA/R do porta-enxerto IAC 313 “Tropical” em função de níveis crescentes de alumínio nas diferentes épocas de coletas (A) e aumento dessa relação nos diferentes níveis de alumínio dos 15 aos 75 dias (B). FCA/UNESP, Botucatu/SP, 2004. 

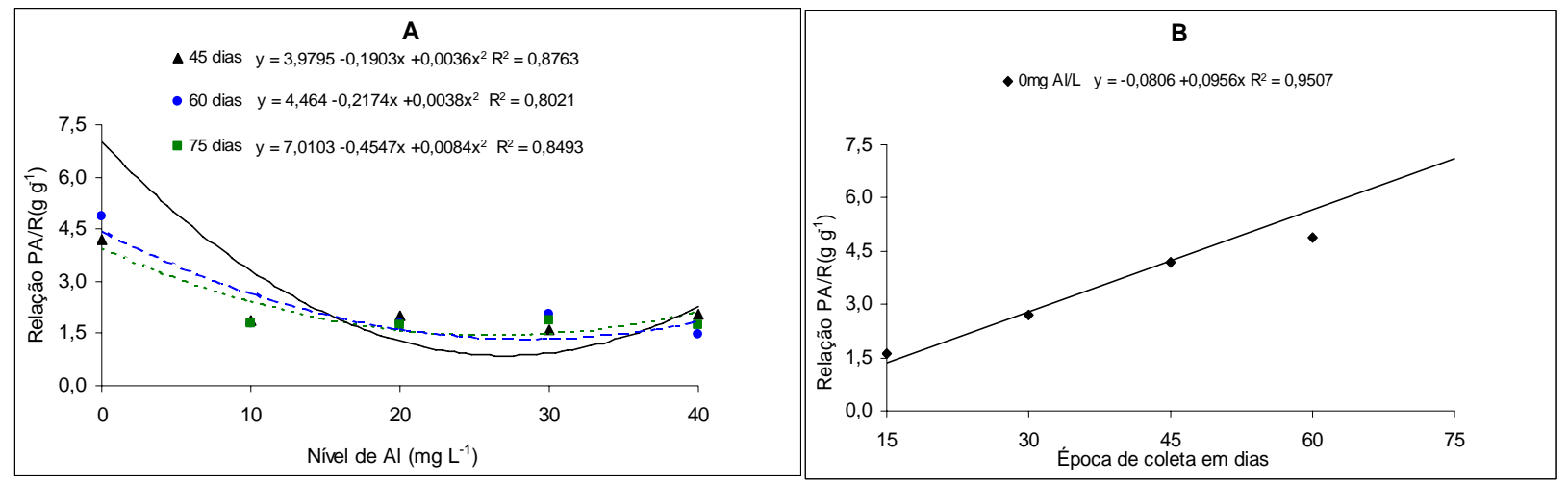

FIGURA 4 - Resultados da relação PA/R do porta-enxerto IAC 572 “Jales” em função de níveis crescentes de alumínio nas diferentes épocas de coletas (A) e aumento dessa relação nos diferentes níveis de alumínio dos 15 aos 75 dias (B). FCA/UNESP, Botucatu/SP, 2004.

A confirmação desses resultados, realizando-se ensaios em campo, é de fundamental importância para se recomendar o porta-enxerto IAC 572 "Jales" para solos com problemas de acidez. Deve-se também verificar o comportamento desse porta-enxerto em áreas com excesso de calagem, pois, de acordo com os resultados aqui obtidos, a ausência total de alumínio na solução teve efeito negativo ao desenvolvimento desse porta-enxerto. De acordo com Foy (1974), em algumas espécies de plantas, o alumínio pode estimular o crescimento ou produzir outros efeitos benéficos, havendo possibilidade de interferir em algumas reações no processo metabólico das plantas. De acordo com esse autor, níveis moderados de alumínio podem ter um efeito benéfico principalmente do sistema radicular.

\section{CONCLUSÕES}

O maior crescimento e desenvolvimento do porta-enxerto de videira IAC 572 "Jales" ocorre com 10 $\mathrm{mg} \mathrm{Al} \mathrm{L^{-1 }}$ solução, ao passo que o porta-enxerto IAC 313 "Tropical", quando submetido a esse nível de alumínio, apresentou um decréscimo acentuado em todas as variáveis avaliadas, mostrando a sensibilidade desse porta-enxerto ao alumínio na solução.

\section{REFERÊNCIAS BIBLIOGRÁFICAS}

AGUIAR NETTO, A. O. Crescimento e produtividade da cultura da batata (Solanum Tuberosum ssp tuberosum) cultivar Aracy, submetida a diferentes lâminas de irrigação. 1997. 87 f. Tese (Doutorado em Agronomia / Irrigação e Drenagem) - Faculdade de Ciências Agronômicas, Universidade Estadual Paulista, Botucatu, 1997.
ALVAREnGA, A. A. Avaliação de cultivares portaenxertos e produtoras de videira (Vitis spp.) em condições de solos ácidos e alumínio. 2001. 153 p. Tese (Doutorado em Agronomia/Fitotecnia) - Universidade Federal de Lavras, Lavras, 2001.

BENINCASA, M. M. R. Análise de crescimento de plantas. Jaboticabal: UNESP, 1988. 42 p.

BENNET, R. J.; BREEN, C. M.; FEY, M. V. Aluminium toxicity and induced nutrient disorders involving the uptake and transport of P, K, Ca and Mg in Zea Mays L. South African Journal of Plant and Soil, Pretoria, v. 3, p. 11-17, 1986.

COSTA, F. Avaliação do estado nutricional da videira cultivar Itália em três estádios de desenvolvimento, na região de Jundiaí-SP, utilizando o método DRIS. 1998. 91 f. Dissertação (Mestrado em Agronomia/Fitotecnia) Escola Superior de Agricultura "Luiz de Queiroz", Universidade de São Paulo, Piracicaba, 1998.

FOY, C. D. Effects of aluminum on plant growth. In: CARSON, E. W. (Ed.). The plant roof and its environment. Charlottesville: University of Virgínia, 1974. p. 601-642.

FOY, C. D. Differential aluminum and manganese tolerance of plant species and varieties in acid soils. Ciência e Cultura, São Paulo, v. 28, n. 2, p. 150-155, 1976.

FOY, C. D. Tolerance of eastern gamagrass to excess of aluminum in acid soil and nutrient solution. Journal of Plant Nutrition, New York, v. 20, n. 9, p. 1119-1136, 1997. 
FOY, C. D.; FLEMING, A. L. The physiology of plant tolerance to excess available aluminum and manganese in acid soils. In: GERALD, A. J. Crop tolerance to suboptimAl Land conditions. Madison: American Society of Agronomy, 1978. p. 301-328.

FOY, C. D.; FLEMING, A. L.; GERLOFF, G. C. Differential aluminium tolerance in two snaphbean varieties. Agronomy Journal, Madison, v. 64, p. 815818, 1972.

FRÁGUAS, J. C. Sintomatologia da toxidez do alumínio em porta-enxerto de videira. Bento Gonçalves: CNPUV/EMBRAPA, 1996. 18 p. (Circular técnico, 20).

FRÁGUAS, J. C. Tolerância de porta-enxerto de videira ao alumínio do solo. Pesquisa Agropecuária Brasileira, Brasília, v. 34, n. 7, p. 1193-1200, 1999.

FREGONI, M. Nutrizione e fertilizzazione della vite. Bologna: Edagricole, 1980. 418 p.

FURLANI, A. M. C.; FURLANI, P. R. Composição e $\mathrm{pH}$ de soluções nutritivas para estudos fisiológicas e seleção de plantas em condições adversas. Boletim Técnico do Instituto Agronômico, Campinas, n. 121, p. 21-26, 1988.

GERGOLETTI, I. F. Avaliação do estado nutricional da videira cultivar Itália em três estádios de desenvolvimento em São Miguel Arcanjo, SP, utilizando o método DRIS. 1995. 84 f. Tese (Doutorado em Agronomia/Solos e Nutrição de Plantas) - Escola Superior de Agricultura “Luiz de Queiroz”, Universidade de São Paulo, Piracicaba, 1995.

HOAGLAND, D. R.; ARNON, D. I. The water culture method of growing plants without soil. Berkeley: California Agricultural Experiment Station, 1950. 32 p.

HUANG, J. W. et al. Calcium fluxes in Al-tolerant and Al-sensitive wheat roots measured by Ca-selective microelectrodes. Plant Physiology, Rockville, v. 98, p. 230-237, 1992.

LOPES, A. S. Solos sob “cerrado”, características, propriedades e manejo. Piracicaba: Instituto da Potassa \& Fosfato, 1983. 162 p.
LUCHESI, A. A. Utilização prática da análise de crescimento vegetal. Anais da Escola Superior de Agricultura Luiz de Queiroz-Universidade de São Paulo, Piracicaba, v. 41, n. 1, p. 181-202, 1984.

MARCELIN, H. La vigne dans les sols acides de Roussillon. Progrès Agricole et Viticole, Montpellier, v. 91, n. 18, p. 570-576, 1974.

MALAVOLTA, E. Elementos de nutrição mineral de plantas. São Paulo: Agronômica Ceres, 1980. 251 p.

MARSCHNER, H. Mineral nutrition of higher plants. 2. ed. San Diego: Academic, 1995. 889 p.

MATSUMOTO, H. Biochemical mechanism of the toxity of aluminium and the sequestration of aluminium in plant cells. Plant and Cell Physiology, Kyoto, v. 45, p. 825-838, 1991.

MEDEIROS, J. G.; PEREIRA, W.; MIRANDA, J. E. C. Análise de crescimento em duas cultivares de batata doce (Ipomoea batatas (L.) Lam). Revista Brasileira de Fisiologia Vegetal, Brasília, v. 2, n. 2, p. 23-29, 1990.

OLMOS, I. L. J.; CAMARGO, M. N. Ocorrência de alumínio tóxico nos solos do Brasil, sua caracterização e distribuição. Ciência e Cultura, São Paulo, v. 28, n. 2, p. 171-180, 1976.

PAVAN, M. A.; BIAGHAM, F. T. Toxidez de alumínio em cafeeiro cultivados em solução nutritiva. Pesquisa Agropecuária Brasileira, Brasília, v. 17, n. 9, p. 12931302, 1982.

RADFORD, P. J. Growth analysis formulae: their use and abose. Crop Science, Guldeford, v. 7, p. 171-175, 1967.

REGINA, M. A. et al. Levantamento nutricional e diagnóstico agronômico dos vinhedos de Caldas. Revista Brasileira de Fruticultura, Cruz das Almas, v. 20, n. 1, p. 15-20, 1998.

RODRIGUES, S. D. Análise de crescimento de plantas de soja (Glycine max L. Merrill) submetidas à carências nutricionais. 1982. 154 f. Dissertação (Mestrado em Biologia/Biologia Vegetal) - Universidade Estadual Paulista, Rio Claro, 1982. 
SANTOS, C. H. Influência de diferentes níveis de alumínio no desenvolvimento de dois porta-enxertos cítricos em cultivo hidropônico. 1998. 134 f. Dissertação (Mestrado em Horticultura) - Universidade Estadual Paulista, Botucatu, 1998.

TERRA, M. M. Carências de macronutrientes afetando o crescimento, concentração, acúmulo, e interação de nutrientes na videira cv. Niagara Rosada, desenvolvida em solução nutritiva. 1984. 221 f. Dissertação (Mestrado em Solos e Nutrição de Plantas) Escola Superior de Agricultura "Luiz de Queiroz", Universidade de São Paulo, Piracicaba, 1984. 